\title{
EL CONVENIO DE SEPARACIÓN DE CERVANTES Y SU MUJER CATALINA
}

El título de esta conferencia ya anuncia una de sus conclusiones. Les propongo examinar un documento entre los muchos firmados por Miguel de Cervantes. Un seco documento notarial, sin interés aparente, escudriñado con conocimiento de sus circunstancias, siempre relevantes, puede brindarnos unos datos y perspectivas preciosos sobre la vida de los firmantes. El que vamos a estudiar no es en absoluto desconocido, se publicó en 1929 y se halla a disposición de todos en la biografía de Luis Astrana Marín ${ }^{1}$. Pero, que yo sepa, no ha recibido ninguna atención especial.

Se trata de un poder que Miguel de Cervantes otorgó a su esposa Catalina de Palacios poco antes de su salida para Sevilla, desde donde recorrería los caminos andaluces en la compra de trigo y aceite para la Armada Invencible. Este detallado poder, otorgado en Toledo el 28 de abril de 1587, ha despertado mi curiosidad desde hace tiempo.

Por dicho documento, que reproduzco como apéndice, Miguel pacta lo siguiente:

- Su esposa, Catalina, puede recibir y cobrar en nombre de su marido cualquier cantidad que le sea debida,y las deudas se darán como canceladas.

- Puede vender cualquiera de los bienes de los dos, muebles o raíces, «a las personas y por los precios que quisiéredes».

1 Vida ejemplar y heroica de Miguel de Cervantes Saavedra. Madrid, Reus, 19481958, IV, 63-67. La transcripción de Astrana Marín corrige notablemente la de García Rey, como aquél señala (IV, 67, n. 1). 
- Miguel se compromete a pagar cualquier deuda que su esposa contraiga, y la pagará "a los tiempos y plazos y en la forma y partes que asentáredes».

- Ella puede tomar la decisión que quiera en cualquier pleito o causa que pueda afectar a él o a los dos, y hacer cualquier demanda, requerimiento o venta.

Todo esto con muchos detalles y ejemplos de las cosas que ella puede pactar, que les ahorro. En fin, «cuan cumplido poder y licencia os puedo dar, tal os le doy y otorgo", dice Miguel. A ella le quita cualquier responsabilidad, y él se obliga a todo: "vos relievo y me obligo de lo haber por firme», y compromete su "persona y bienes habidos y por haber».

Es un compromiso completamente unilateral. Miguel da a su esposa, en efecto, no sólo todo lo que posee, sino todo lo que gane o reciba en el resto de su vida. Se compromete a todo y rehúsa comprometer a su mujer a nada. Un poder tal, debo aclararles, no es ni frecuente ni normal. No he visto otro parecido, y a estas alturas ya he leído bastantes documentos del Siglo de Oro.

El acontecimiento que al parecer ocasionó este poder -así se ha entendido hasta ahora - fue el traslado de Cervantes a Sevilla y su empleo como Comisario de la Armada. Ahora bien, la ruta de Toledo a Sevilla era la más transitada de España en la segunda mitad del siglo dieciséis. Era un viaje rutinario, con ventas frecuentes. Duraba aproximadamente diez días (Astrana, IV, 71), y Cervantes, en efecto, iría y vendría a menudo a Sevilla.

Cuando gestionó este poder, no estaba a punto de embarcarse para las Indias. Si hubiera sido así, acaso se podría entender el documento: no hubiera sabido si llegaría y menos si volvería, y la comunicación con España era muy lenta. Pero ¿estar en Sevilla? Si se presentara, por ejemplo, un pleito para el cual hiciera falta su presencia, en tres semanas podría estar en Madrid: diez días para que el aviso le llegara, y otros diez para el viaje. No era necesario, o tan necesario, que su mujer actuara por él. El documento es evidentemente algo más que una simple autorización para que Catalina defendiera sus intereses, estando su marido ausente.

El contenido del documento se entiende mejor tomando en cuenta las relaciones entre Miguel y Catalina, y a la vez contribuye a perfilarlas. Miguel era un autor que hablaba a menudo de sí mismo: de su vida, su carrera, sus logros, sus proyectos. En todas estas autopresentaciones no se refiere ni una sola vez a su mujer. En sus obras el tema que le interesa es el amor, pero los matrimonios felices son aquellos en los que la mujer apenas aparece, como los del Caballero del Verde Gabán y de Antonio Moreno. Los matrimo- 
nios más detalladamente descritos, el de Sancho y Teresa Panza y el de Carrizales, el celoso extremeño, son desgraciados. El matrimonio de Cervantes y Catalina fue estéril. Por último, Cervantes vivió mucho tiempo, al parecer años enteros, a solas, sin su mujer, y viajaba mucho. Cervantes fue también quien estrenó en la literatura española el tema del divorcio.

Éstos son los datos que tenemos. No sugieren una relación feliz, alegre ni descansada. Todo lo contrario. Sugieren una pareja que se llevaba mal. Ignoro cuál marido pudo ser Miguel. Era un antiguo soldado, manco, recién vuelto a España tras cinco años de cautiverio en África del Norte, sin empleo que conozcamos, pero también autor de una novela publicada y de comedias representadas. Era un hombre con muchas ideas sobre el amor, quien incluso leyó a los teóricos italianos sobre el tema ${ }^{2}$. El amor fue tema principal de La Galatea, acabada precisamente en $1584^{3}$ y publicada en 1585.

Se casa con una mujer a la que dobla la edad: ella diecinueve años y Miguel treinta y siete (Astrana, III, 456). Catalina sabía firmar, pero sin duda leía poco o nada. Fue vecina de un pueblo toledano, cuyas únicas salidas quizás hayan sido a Toledo o a Madrid, y aun esto no consta. Me imagino, dada la atención prestada a la belleza femenina en las obras de Cervantes, que habrá sido muy bonita.

Miguel y Catalina eran dos personas muy desiguales: la mujer del pueblo y el hombre del mundo, la mujer inculta casada con un pensador, bibliófilo y autor. Las teorizaciones y lucubraciones de Miguel sobre el matrimonio - un estado sacramental, que combina dos cuerpos en uno y permite la satisfacción sexual del varón al mismo tiempo que garantiza el bienestar económico de la mujer y progenie- le habrán interesado poco o nada. Tampoco su concepto, claramente expresado en sus obras, de que la mujer debería obedecer al marido, siempre más sabio.

Para el colmo, se conocieron sólo dos meses antes de casarse para toda la vida. No me parece exagerado calificar todo esto como la receta para un desastre. Cada uno es artífice de su ventura, nos recuerda Cervantes, y tenemos que concluir que él mismo lo fue de su desventura matrimonial. Es autor de un entremés «El juez de los divorcios». Aunque en esta obrita el divorcio se presenta como un medio para que los abogados y notarios se enriquezcan, y que «más vale el peor matrimonio que no el divorcio mejor», según

\footnotetext{
$255-276$

2 GeOFFrey STAGG, "Plagiarism in La Galatea», Filologia romanza, 6, 1959,

3 Su aprobación es del primero de febrero de 1584.
} 
cantan los músicos al final, se concluye que Cervantes había meditado el tema. En «La gitanilla» también lo trata.

Me atrevo a sugerir, entonces, que los empleos de Miguel como comisario y después como recaudador, que le ocasionarían prolongados viajes y estancias por tierras andaluzas, no tenían su origen en una simple necesidad económica. Un hombre con su talento administrativo y sus enchufes podría haber hecho otras cosas. Creo percibir ganas de ausentarse de una casa donde no se hallaba a gusto ni incluso querido. Se separa física y geográficamente de su mujer, y entra en otra etapa de su vida. Miguel y su esposa volverían a vivir juntos, muchos años después, aunque también con interrupciones; su vida de pareja es tan atípica, que se señalan las ocasiones en que ésta se produjo.

Miguel, entonces, se separó voluntariamente de su mujer. Una separación tal habrá reflejado la opinión de que viviría mejor sin ella que con ella: un matrimonio fracasado.

Hoy en día el divorcio existe en todos los países industrializados. Nos olvidamos a veces de lo reciente que es este estado de cosas. En el mundo musulmán, incluido naturalmente al-Andalus, el divorcio para el varón (no la esposa) era fácil. La España cristiana, en cambio, fue campeona de la mujer. Con la breve excepción de la Segunda República, no permitiría el divorcio hasta después de la muerte de Franco, casi acabado el siglo veinte. Aun en los Estados Unidos, el divorcio ha sido bastante más difícil que hoy en día, o en un estado como la Carolina del Sur simplemente no existía. Me imagino que muchos de ustedes, como yo, estarán divorciados. Piensen cómo serían sus vidas si el divorcio no existiera y si estuvieran casados con su antiguo esposo o esposa, sin otra salida que «la pala y el azadón» ${ }^{4}$.

Pero la inexistencia del divorcio no ha implicado que el marido tuviera que vivir con su mujer. Lo que tenía que hacer es mantenerla. Y a eso se obliga Miguel. Con la sospecha de que el documento aludido respondiera a una decisión de Miguel de ausentarse de la casa matrimonial, consulté, por intervención de José María Casasayas, a dos especialistas en la historia de la notaría ${ }^{5}$. Los dos me confirmaron la misma sospecha. Con este poder Miguel se protegía contra un cargo de abandono de la mujer, un crimen, aunque raramente procesado. En un mundo sin carnés de identidad, teléfonos ni aviones, cambiar de piel era sencillo. Desaparecer y apare-

${ }_{4}$ Es lo que pasó en España al final de la guerra civil. Los divorcios de la República se nulificaron y todos los interesados se encontraron de nuevo casados con sus antiguos cónyuges. Mallorca.

Se trata de Raimundo Clar Garau y Bartolomé Torres Serra, de Palma de 
cer en otra parte de España, o del mundo, con un nombre diferente era más que fácil. Pero Miguel no quería, o no podía, desaparecer. Tomó esta medida - separarse de Catalina - por el camino legal que existía entonces ${ }^{6}$.

\section{CONCLUSIONES}

Miguel reconoció su matrimonio como un fracaso en 1587, a los dos años de casados. No quería vivir más con su mujer (ni, posiblemente, ella con él). Se ausentó de ella por años enteros. Pero también se descubre en Miguel una persona formal, consciente de sus responsabilidades. No se relaciona con ninguna amante después de casado. La hija «natural» que tuvo, Isabel, es anterior a su casamiento. Y también por documentos se descubre que no abandonó a Isabel, ni negó su responsabilidad hacia ella. Al contrario, la recibió en su casa, so pretexto de criada, protegió sus intereses y le consiguió una buena dote. Es la conclusión extraída de los documentos, que constituyen el único conducto por el cual hemos llegado a tener conocimiento de la existencia de esta hija, además de las circunstancias de su matrimonio.

Miguel fracasa en su única experiencia y oportunidad en el matrimonio. Pero es una persona cautelosa y responsable, hasta idealista. Le importan las estructuras de la sociedad. Quiere que funcionen. Es el tipo de hombre al que uno encargaría grandes sumas de dinero para compras, o el recaudo de los impuestos del rey.

\section{DANIEL EISENBERG \\ Regents College}

6 No consta ni que Catalina haya usado los poderes otorgados en este documento, ni que Miguel lo revocara. 


\author{
APÉNDICE \\ Poder de Miguel de Cervantes Saavedra \\ a su esposa Catalina de Salazar y de Palacios, \\ 28 de abril de 1587
}

Sepan cuántos esta carta de poder vieren, como yo, Miguel de Cervantes Saavedra, vecino del lugar de Esquivias, jurisdicción desta ciudad de Toledo, otorgo y conozco que doy y otorgo mi poder cumplido, bastante, según que le tengo y de derecho se requiere y más puede y debe valer y licencia y facultad bastante en forma,

a vos, doña Catalina de Salazar y de Palacios, mi mujer, que estáis ausente,

especialmente para que por mí y en mi nombre y en el vuestro podáis demandar, recibir, haber y cobrar todos y cualesquier maravedís, pan, trigo y cebada y otras cualesquier cosas que a mí o a vos son y fueren debidas y pertenecientes por cualquier persona y personas vecinos de cualesquier partes, ansí por obligaciones, cédulas, conocimientos y cuentas de libro, o sin ellas, como en otra cualquier manera, y de lo que recibiéredes y cobráredes podáis dar y otorgar vuestras cartas de pago y finiquito y lasto, que valan [sic] como si yo las diese y otorgase siendo presente,

y para que podáis vender y vendáis cualesquier vuestros bienes y míos, ansí muebles como raíces a las personas y por los precios que quisiéredes, fiado o de contado, y recibir el precio de maravedís y otras cosas por que los vendiéredes, y otorgaros por contentos [sic] dellos; y si la paga no pareciere de presente, ante el escribano, renunciar la exención de la no numerata pecunia y leyes de la entrega y prueba de la paga, y desistirme y desapoderarme de la tenencia y posesión de los dichos bienes y embestir y apodar en [roto el papel, falta «ellos a»] las personas que los compraren y darles poder para tomar la posesión dellos, y en el entretanto constituirme por inquilino;

y para que me podáis obligar, juntamente de vos, de mancomún, renunciando las leyes de la mancomunidad y el beneficio de la división y excursión a la renta y lición y saneamiento de los dichos bienes que ansí vendiéredes, a que los haré ciertos y sanos, seguros y de paz a las personas que los compraren, y en ellos no les será puesto embargo ni impedimento; donde no, lesvolveré el precio de maravedís y otras cosas que por ellos dieren;

y para que en razón de cualesquier pleitos y diferencias que yo y vos tenemos y tuviéremos con cualesquier persona o personas, os podáis concertar y dejar en manos de jueces árbitros que lo vean, sentencien y determinen por justicia o amigablemente, o en otra cualesquier manera, y 
para que me podáis obligar y obligaros, juntamente y de mancomún, a la paga de cualesquier maravedís que debiéremos, ansí de deudas contraídas hasta hoy, como por razón de cualesquier mercaderías y otras cosas que compráredes como por fiadores de cualesquier personas y en otra cualquier manera, para que pagáremos los tales maravedís a los tiempos y plazos y en la forma y partes que asentáredes, con sumisión a cualesquier justicias, y renunciación de nuestro propio fuero, y sobre ello, por ante cualesquier escribanos que a ello sean presentes, podáis hacer y otorgar cualesquier escrituras, con todas las fuerzas y firmezas, penas, obligaciones, renunciaciones de leyes y sumisiones que para su validación se requieran; que según por vos fuere fecho y otorgado lo susodicho, yo lo otorgo y me obligo al cumplimiento dello, como si por mí fuera otorgado;

y generalmente os doy y otorgo este dicho poder para en todos mis pleitos y causas, y vuestros, civiles y criminales, movidos y por mover que habemos y tenemos y esperamos haber y tener con cualesquier persona o personas, y cualesquier jueces y justicias y hacer sobre ello todas y cualesquier demandas, pedimientos, requerimientos, citaciones, posturas, embargos, ejecuciones, prisiones, ventas y remates de bienes y juros, presentar cualesquier escrituras y probanzas y otro género de prueba, pedir e [roto el papel] cualesquier sentencia y sentencias ansí inter [roto el papel] como definitivas, consentir en las de nuestro favor y apelar y suplicar de las de contrario, y los seguir en cualesquier juicios e instancias, y hacer todos los demás autos y diligencias que sean necesarias, ansí judicial como extrajudicialmente; e para que podáis sustituir un procurador, dos o más, y los revocar, y poner otros de nuevo;

que cuan cumplido poder y licencia os puedo dar, tal os le doy y otorgo, con libre y general administración y con lo a ello anejo y dependiente; y vos relievo y me obligo de lo haber por firme, so obligación que hago de mi persona y bienes habidos y por haber.

En firmeza de lo cual, otorgué esta carta ante el escribano público y testigos de yuso escritos, que fue fecha y otorgada en la dicha ciudad de Toledo, veinte y ocho días del mes de abril de mil y quinientos y ochenta y siete años. Y el dicho otorgante lo firmó de su nombre, al cual yo el presente escribano doy fe que conozco.

(ASTRANA, IV, 63-67, modernizada la ortografía y dividida en párrafos.) 